\title{
From Atoms to Stars: Meghnad Saha (1893-1956)
}

\author{
Atri Mukhopadhyay*
}

(Received 7 May 2018; revised 22 June 2018)

\begin{abstract}
Saha Ionization Theory and its immediate applications in the West is discussed. While this work, performed at a place far from the-then meccas of science, led to a spate of activity, the man behind it suffered isolation.
\end{abstract}

Key words: Harvard classification of stars, Thermal ionization.

\section{INTRODUCTION}

Meghnad Saha, the founder of modern astrophysics, took his maiden trip abroad in September, 1920. The University of Calcutta, where he was a lecturer in Physics since 1918, accorded him the Guruprasanna Ghosh Travel Fellowship for 3 years. Of this, a year got lost in writing and getting accepted the papers on the theory of thermal ionization that he worked out in 1919. A D.Sc. of the University (1918) for his research in electrodynamics, Saha received in 1919 both the Premchand Roychand Studentship (PRS) and the Griffith Memorial Prize of the University on the merit of some consequences of his theory.

He headed for London to verify his theory experimentally. His friend Snehamoy Dutta, working with Alfred Fowler, the noted spectroscopist at the Imperial College, inspired him to seek a visiting position there (Chatterjee, 1984).

Saha's theory holds that stellar temperature is so high that the elements therein are mostly ionized. The-then European physicists like Eddingon, Jeans and Lindemann had guessed as much, but not to much avail. Saha noticed, one- ionized atom reproduces the spectrum of the atom of preceding atomic number, with 4 multiplying the Rydberg constant. Following John Eggert (1919), he then treated ionization as a two-way chemical reaction, and employing Nernst's reaction isobar, obtained an equation for the degree of ionization in terms of the heat of reaction, ambient pressure and temperature. While Eggert's choice of the heat was arbitrary, leading him nowhere, Saha associated it with the ionization potential of the atom. His equation says, the lower the ionization potential and the pressure, and higher the temperature, the higher the degree of ionization. Using the few available experimental values of ionization potentials and taking reasonable values of solar pressure, Saha concluded that the elements taken to be absent in the sun are all there, albeit ionized.

The concept resulted in four papers in a row (Saha, 1920 - 21): 'Ionization in the solar chromosphere' (paper I, sent on $4^{\text {th }}$ March); 'Elements in the sun' (paper II, 22 ${ }^{\text {nd }}$ May); 'On the temperature radiation of gases' (paper III, $25^{\text {th }}$ May) and 'On the Harvard classification of stellar spectra' (paper IV). The last was based on his PRS thesis (1919) and, the essay for the Griffith Memorial Prize with suitable changes. Getting the

\footnotetext{
* Formerly at Saha Institute of Nuclear Physics, Kolkata. Mailing address: FD 3/4, Sec III, Bidhannagar, Kolkata-700106, Email: atri.mukhopadhyay@saha.ac.in
} 
first paper accepted met with difficulties. Saha requested John Evershed to communicate it to the Monthly Notices of Royal Astronomical Society (MNRAS), but Evershed declined (Saha, 1955) as he could not understand the paper. Saha then sent it directly to the MNRAS. It was refused forthwith. Finally, it got accepted in Philosophical Magazine. So were the rest. While the contents of the first three papers are discussed later, we presently consider the fourth addressing a certain oddity.

It was known for several decades that 99 per cent of the stars fall in the so-called Harvard sequence, namely O B A F G K M R N S with the colour changing from blue to red. The spectra have the continuity that as we move from right to left along the sequence, a line appears, becomes more and more intense and then starts fading away to zero visibility when a new line appears, and the story repeats. The regularity was a mystery (Venkataraman, 1995).

Saha held temperature a key factor, increasing from $\mathrm{S}$ to $\mathrm{O}$. Then he argued as follows. The intensity of a line depends on the number of atoms contributing electrons to the initial of the two atomic energy levels involved in the transition. Suppose the temperature in a class of stars (say $\mathrm{R}$ ) is such that the electrons of all the atoms are mostly at the lowest energy level 1 and only a few in the next upper level 2. The transition 1 to 2 will ensue as we move to the type $\mathrm{M}$ and a dark line will appear. Its intensity will keep increasing as we move to the next type $\mathrm{K}$, as more and more electrons will jump from level 1 to 2 . As we move on, the temperature becomes so high that atoms start feeding electrons not to level 1 but to the next higher level 2. The intensity of the 1-2 line then starts falling, eventually reaching zero while a new line 2-3 shows up and goes on gaining intensity until we reach the class where all the atoms are ionized; here we have the same set of levels but displaced upward, and the story repeats. If in a certain class of stars we find that any spectral line has vanished, it means ionization is complete.
Thus while appearance of such a line indicates onset of ionization, vanishing of it means ionization is complete. From this, Saha estimated the surface temperature of a star and the relative abundance of elements therein.

\section{Saha in Europe}

In October, 1920 Saha joined Fowler. Having discussed with him his fourth paper, Saha called it back for a revision. Much later he reminisced (Saha, 1946), 'Though the main ideas and working of the paper remained unchanged, the substance matter was greatly improved on account of Fowler's kindness in placing at my disposal fresh data, and offering criticism'.

The revised manuscript, now titled 'A physical theory of Stellar Spectra' was communicated by Fowler to the Proc Roy Soc A on 18 January 1921. The method for estimating the stellar temperature and elemental composition was later improved by Cecilia Payne in the USA (Payne, 1925).

Still obsessed with a verification of his theory, Saha gathered from Eggert in Berlin that his supervisor Nernst, having the facilities Fowler lacked, would welcome Saha. In February 1921, he migrated there. Leaving London so soon did not much please Fowler, and precipitated some complication with Saha's parent university. This, however, was resolved by the kind intervention of Fowler giving Saha a good certificate (Mukhopadhyay, 2012). In Berlin, work on cesium was successful, but for other elements, Saha needed still higher temperature.

The next summer, during the Empire Universities Congress at Oxford, Saha, a delegate ofCalcutta University, explored possibilities there. Professor Herbert Hall Turner advised him to contact the Mount Wilson Observatory in the States. By then, all his papers were out in print, I in October 1920, II in December, 1920, III in February 1921 and IV in May 1921. At Sir Arthur Stanley Eddington's place in Cambridge, Saha met 
Eddington's assistant, Edward Arthur Milne (Sen, 1954).

Back in Berlin, he wrote (Saha, July 9, 1921) to George Ellery Hale, director of the Observatory, appending a summary of what he had done and a list of what else could be explored. He wrote, (a) in paper I, he had explained the exclusive occurrence of the lines of $\mathrm{Ca}^{+}, \mathrm{Sr}^{+}, \mathrm{Ba}^{+}$in the upper chromosphere, and the disappearance of the lines of $\mathrm{Ca}^{+}, \mathrm{Sr}, \mathrm{Ba}$ from this region. He was yet to explain the occurrence of lines $\mathrm{Ti}^{+}, \mathrm{Fe}^{+}, \mathrm{Mn}^{+}, \mathrm{Va}^{+}$ etc. which required a knowledge of the ionization potentials of these elements. He suggested that an attempt might be made to obtain the $1 \mathrm{~S}$-terms of these elements from spectroscopic data and investigate the enhanced lines of these elements (e.g., $\lambda \lambda 5018,4924$ in the case of $\mathrm{Fe}^{+}$), (b) on p. 815 of paper II, he had explained the apparent absence of $\mathrm{Rb}$ and $\mathrm{Cs}$ as being due to the fact that they are completely ionized in the Sun, and the lines of $\mathrm{Rb}^{+}$and $\mathrm{Cs}^{+}$, unlike those of $\mathrm{Sr}^{+}$and $\mathrm{Ba}^{+}$ lie too far in the ultraviolet. The resonance lines of $\mathrm{K}, \mathrm{Nb}, \mathrm{Cs}$ all lie in the infrared and should come out in the spot spectrum, if the investigation were to be carried out to $\lambda 9000$. These points might be tested in the Mount Wilson Observatory. On p 824 he has pointed out that the spectra of Faculae might be similar to the spectra of F-class of stars. (c) In paper IV, he has considered the varying intensity of the characteristic lines of $\mathrm{Ca}, \mathrm{Ca}^{+}, \mathrm{Mg}, \mathrm{Mg}^{+}, \mathrm{H}$, $\mathrm{He}, \mathrm{He}^{+} \mathrm{Sr}$ and $\mathrm{Sr}^{+}$. But there was a large number of other stellar lines which might be investigated from the same standpoint, e.g., Mn (4030 group), $\mathrm{Mn}^{+}$(3442 group and 4344.4 group), $\mathrm{Fe}$ (4583 group), $\mathrm{Fe}^{+}\left(4255,5016\right.$ etc), $\mathrm{Ti}^{2} \mathrm{Ti}^{+}, \mathrm{C}, \mathrm{C}^{+}, \mathrm{Si}$, $\mathrm{Si}^{+}, \mathrm{O}, \mathrm{O}^{+}, \mathrm{N}, \mathrm{N}^{+}$etc. In paper III, he had discussed some of Arthur King's experimental results on spectroscopy of heated gases. On 29 July, Saha sent HN Russell, a Professor of Astronomy in Princeton, reprints of his papers I and II.

\section{VoICe OF THE West}

Hale passed the letter to Russell, then a Visiting Research Associate at the Mt Wilson
Observatory. Russell had already read paper I. As early as 17 December 1920, he wrote to his experimentalist friend Walter Sydney Adams of the Mt Wilson,

Have you read a paper by Megh Nad Saha, in the last Phil Mag on Ionization in the Chromosphere? I found it extremely suggestive; and I believe that within a few years we may utilize knowledge of ionization potentials, and so on, to obtain numerical determination of stellar temperature from spectroscopic data - or at least of relations between temperature and pressure. Saha's conclusion that low pressure and density are extremely favorable to double ionization and the appearance of enhanced lines is very interesting in connection with the remark which I remember in a letter of yours years ago, to the effect that the absolute magnitude lines for giant stars are all enhanced lines. At equal temperatures, the low density of the giant stars should directly favor the appearance of such lines.

He went on,

Saha's calculation about the dissociation of hydrogen seems to solve a problem that always puzzled me, namely why do not we get the secondary spectrum of hydrogen in astrophysical spectra? We calculate that dissociation should be complete except at considerable pressure (and) temperature below 4000. At 3000, however, there should be a good bit of molecular hydrogen if the pressure was high. Now the familiar hydrogen lines are almost absent in the dwarf M stars, though fairly strong in giants of the same type - which led me to suggest that careful study of the spectra of dwarf M's, to see whether the secondary hydrogen spectra can be found, might well (be) worthwhile. You have the best existing spectra of such stars. Might it not (be) an amusing thing to try? (Russell Papers).

By then, Russell had already published an article in Scientific American of July 21921 underlining the importance of Saha's work (Venkataraman, 1959). He now concentrated on exploiting the new explanatory framework provided by Saha. Much of the work that remained isolated at Hale's laboratory could now be consolidated (DeVorkin, 1993).

On July 2, 1921 Russell had also dispatched to Publication of the Astronomical 
Society of the Pacific (PASP) another paper entitled 'Rubidium in the Sun'. The opening paragraph of it read,

Dr MN Saha [Phil Mag 40 (1920):814] predicts that the principal lines of rubidium, which are invisible in the solar spectrum, should appear faintly in the spectra of sun-spots. The search for them is made an easy matter by the recent publication of extensive and accurate tables of wave-lengths in the extreme red, both in the solar spectrum and in the arc, and by the existence at Mount Wilson of a fine set of plates of the spotspectrum extending to $\lambda 8200$, taken by Mr Brackett with the 150-foot tower telescope and 75-foot spectrograph, in the first order, and with Nicol prism and compound quarter-wave plate.

Continued he,

On examination of these plates rather conspicuous spot-lines were seen very near the known positions of both lines of the principal pair of rubidium. These lines are strictly confined to the spot, are rather diffuse, show a strong Zeeman effect, and resemble in all particulars the well-known lithium line at $\lambda 6708 \ldots . .$. . The presence of rubidium in the Sun appears to be established (Russell, 1921).

The next day, having acknowledged the two letters, Russell (Russell papers) wrote to Saha that he had long wished to write to thank him for the reprints of his first two papers and to tell him of the very high opinion which he held of his work. In his opinion, Saha had made a great contribution to astrophysics which was of the highest value and importance and opened great opportunities for future advance. He assured Saha that his predictions about the lines of alkali metals in the sun-spot spectrum were completely verified. "Rubidium is present". The lines of the alkaline earths also behaved in a manner which agreed very remarkably with Saha's theory - except that the spectroscopic evidence indicated that barium was a good deal more easily ionized than sodium. By comparison of the behaviour of the lines of other elements he found data strongly supporting Saha's conclusion that the ionization potential of $\mathrm{Ti}, \mathrm{Fe}$, $\mathrm{Co}, \mathrm{Ni}$ - Ce lay between 6 and 9 Volts. However, he was curious to know how Saha got these values.
Russell added, 'Hale, Adam, St. John and other members of the staff here were greatly interested in the various applications of the ionization theory'. They have already discussed the desirability of work along all the lines suggested in his letter and it was probable that a great deal would be done at Mt Wilson or Cal Tech. Russell assured, at Mt Wilson they would investigate cesium as soon as proper photographs of the spot spectrum near $\lambda 6500$ were available. He also enclosed for Saha's perusal a carbon copy of the notes prepared for the said PASP. He added that he had noted several points on which Saha's theory could be fruitfully modified, for example, by including effects of ionization of several elements rather than one - as Saha had assumed for simplicity.

On 5 August 1921, Russell addressed a gathering of the Pacific Division of the American Association for Advancement of Science in Berkeley, elaborating in glowing terms how Saha's Ionization Theory would help science possess a 'rational theory of stellar spectra, and, at the same time, much additional knowledge concerning the constitution of atoms'. Little did he know, Saha, in his revised paper IV had already addressed the first part of what Russell envisaged.

While Russell was busy exploiting Saha's work, Milne and Ralph Fowler at Cambridge (UK) initiated several projects based on it. On 1 June 1921, Milne, already having paper I, asked Saha for a reprint of his paper IV (Milne, 1921), for he was to write a note on Saha's papers for the Observatory. But strangely, Milne called it SahaEggert-Lindemann theory. While Eggert's name is not unexpected, Milne (Milne, 1935) wrote to Saha,
Lindemann always seems to me to be rather jealous of your work - he has never forgiven himself for not discovering the physical nature of the stellar sequence himself, which we all recognize was due to you.

By adding Lindemann's name, Milne was perhaps trying to keep his difficult colleague at Oxford in 
good humour. However, with Russell's persistent use of Saha's name alone, the other names eventually dropped out (DeVorkin 1993).

On October 14, 1921, Russell (Russell papers) wrote to Eddington,

My two months at Mt Wilson were even better than I expected. I got very much interested in application of Saha's Theory of Ionization and have a paper in press, confirming all the predictions and adding some new material....Please give my congratulations to Milne on his admirable presentation of the Ionization Theory in the Observatory.

That appeared on November 8, 1921. The same day, he wrote to Adams,

I am much interested to hear of St John's work on the faculae. It is really what one should have expected, but Saha got ahead of us, as on several other occasions. Have you ever tried, by the way, such as we use on the stars, to get its spectral type? It would illuminate things considerably if we could describe the Sun as a G0 star with F8 faculae and N2 spots.

On November 9, King added a postscript in his letter to Russell, saying,

I want to look closer into the matter of lines appearing in absorption before emission. Saha may be right as to the initial appearance. My experiment shows that with a well developed spectrum the emission and absorption for the same thing are very nearly identical.......

A week later (ibid, November 16, 1921) Russell replied,

I am very glad to hear that you have confirmed the effect of strontium $\lambda \lambda 4078$ and 4216 . Another element of great interest is barium. You remember that I found that barium in the Sun appears to be much highly ionized than Sodium, although on Saha's theory they should be equally ionized. Experiment in the furnace with barium alone, barium and potassium, and barium and sodium should show whether the peculiar behaviour is exhibited also in the laboratory. The critical lines are $\lambda \lambda 4554,4934$ as compared with $\lambda 5536$.

The same year, between October 20 to December 2, Russell and Samuel A Mitchell of
Leander McCormick Observatory, Virginia exchanged views on something Saha claimed in respect of coronal temperature, with which they did not agree. Mitchell wrote to Russell (Russell papers),

Apparently Saha is not very well up on matters of Astronomical interest, and being a physicist we could not expect him to be. His values of $7500 \mathrm{~K}$ for the Sun was very surprising.

\section{The Aftermath}

Russell had foreseen two things. One, that mixing has an effect on ionization in the main, for he had seen, even a trace of Cs suppresses the $\mathrm{H}$ ( $\lambda$ 3968) and $\mathrm{K}(\lambda 3933)$ lines of $\mathrm{Ca}^{+}$, and two, that barium, with two electrons in the outer shell was a different story.

Saha eventually acceded (Russell papers, April 26, 1922) that mixing does indeed modify ionization in the main. As to Russell's question how he got the ionization potentials, he answered, either from the published tables or by simple guesswork. After getting to know, from Saha's letter, of Catalan's work on Mn at Fowler's laboratory, Russell rushed to Alfred Fowler a request to pass on to him the results of Catalan.

While his work spurred a hectic activity in the West, Saha, now the Khaira Professor, had been languishing in Kolkata in isolation. On 26 April, 1922 he wrote to Russell,

my best thanks to you for the interest which you have created for my work.... As to the why the alkaline earths as a rule are more ionized than their IP would indicate, I believe I have just got an explanation.

On that Russell much later (ibid, January 24, 1927) confided in Shapley that, unless he misunderstood Saha, he assumed that excited atoms have a sensitive side (Steric factor) on which collision must occur to produce effects, and this did not look to him like good quantum physics. Russell solved this problem by invoking what we now call Russell-Saunders coupling (Russell, 1925). 
Russell nominated Saha to the Committee of Spectral Classification of the International Astronomical Union in Rome (Russell papers, June 23, 1922). Later (ibid, 14 November, 1923), he informed Saha that recently Adams and AH Joy got some spectra of faint dwarf stars which beautifully confirmed his predictions. The aluminium lines between $\mathrm{H}$ and $\mathrm{K}$ appeared stronger than the latter pair (which nevertheless were heavy lines). The titanium triplet at $\lambda \lambda 5210$, 5192,5173 were stronger than the magnesium triplet $\lambda 5183$ etc. The former were ultimate lines, and the latter belonged to a subordinate series. So everything was just as Saha had predicted. Five years later (ibid, 30 August 1928), Saha congratulated Russell for his 'titanic work' on titanium spectra. By January 1933, Russell had finished the vanadium arc spectrum work.

On 17 November, 1935, Saha wrote to Russell (ibid), 'I have read with much interest your George Darwin Lecture published in the Monthly Notices. It was very kind of you to have referred to my early works in such glowing terms'. In 1936, when he met Russell at Harvard, Saha theory had been harnessed to the full.

\section{A Despondent SAHa}

On 21 December, 1946, Saha (Saha, 1946) wrote to Harry H Plaskett, the Savillian Professor of Astronomy at Oxford and President of the Royal Astronomical Society, with a request to send copies of it to Milne and Chapman. One of them sent it to Shapley, and he, in turn, to Russell. Saha wrote from a feeling of his experience during his two visits to Britain. It seemed, there was a persistent effort on the part of British scientists to minimize Saha's early contributions to Astrophysics. This was borne out by Plaskett's remarks in the presidential address published in the Observatory, April 1946, where he had said,

Saha, working in Fowler's laboratory after the end of the last War, then demonstrated that the successive appearances of these different spectra could be interpreted as being due to the temperature and pressure prevailing in the stellar atmosphere. His work had in turn been put on a firm theoretical basis by RH Fowler and E Milne, working at Cambridge and using the magnificent material accumulated by Lockyer, and so successfully interpreted by Baxandall.

Saha retorted,

I regret to tell you that this remark is entirely gratuitous and misleading. It gives one the impression that I derived all the fundamental ideas in astrophysics which goes under my name viz., The Theory of Thermal Ionization and its Applications, from Prof A Fowler, while I was working as a scholar under him in 1920. This is entirely misleading, for I worked at Fowler's laboratory as a guest, and never registered my name as a scholar and the work had been mainly done in India before I went to Fowler's laboratory. For the information of yourself and other scientists who are of this opinion, I may trouble you with a little biographical sketch.

There followed a 10 typed-page long history which is known to most of us where he even added, 'I had to encounter at Calcutta the persistent ill will and hostility of CV Raman, who had been appointed Palit Professor of Physics in 1918'. A similar letter was written later to M G J Minnaert, Director of the Observatory, Utrecht (Saha 1955) in which Saha said, 'The thermal ionization theory gained acceptance only when my paper on A Physical Theory of Stellar Spectra was admitted by the Royal Society of London through the good offices of the late Professor Alfred Fowler... It is quite wrong to say, as Plaskett and others sedulously propagated, that I owed the ideas to Fowler. The equation of thermal ionization was evolved in India in 1919, as Phil Mag paper shows, a year before I met Fowler... But (because of) the propaganda by Plaskett and others I have been hardly given any viable form of recognition by astronomical societies for the work on thermal ionization, e.g., I have never been asked by the Royal Astronomical Society of Great Britain to become their Honorary member, or was awarded any other form of honour'. Saha, however, was elected FRS in 1927. 
Russell's observation on Saha's letter to Plaskett makes an interesting reading. On February 13, 1947, he addressed Shapley (Russell papers),

Saha's history of life is really interesting, and as good an example I know of the importance of providing assistance to a competent man. I had often wondered why Saha's activity in the theoretical field fell off after his return to India, and his account gives the explanation. Whether he is correct in his opinions about Raman I cannot judge but it is a pity that he was buried earning his living in a small position. Unfortunately, the interruption lasted so long that his recent contributions to theory do not seem to me to be at all of the same importance as the old. His history affords a very good argument that the Indian universities and perhaps the government should be actively interested in securing proper opportunities for men of proven abilities. If it would be of any use to you to quote me to that effect you are most welcome to do so. I have always been careful to give Saha the credit for starting the astrophysical application of the ionization theory. I do not think I knew till seeing this letter how much he had done previously in India.

An apologetic Plaskett, while thanking Saha for the letter, replied (Plaskett, 1947),

What was quite new to me was the fact that the early part of your work had been done in India, not Germany, before you came to Fowler's laboratory. The knowledge that you had done so much without help and backing in India only serves to increase the admiration that I have always felt for your great contribution in astrophysics. I only regret that I did not know of this at the time of my presidential address, and can only ascribe my ignorance to a probably incorrectly remembered statement of Russell on his return from England in the early 1920's.

\section{Conclusion}

Saha's work, performed away from the much happening places in science, stimulated a spate of activity in astrophysics in the West. Eddington (Eddington, 1926) wrote,

A very fertile line of investigation was initiated when MN Saha first brought together the observational indications of the state of ionization in the outside of the stars and the modern thermodynamical theory of ionization. By Saha's theory all the details of stellar spectra become quantitatively connected with the temperature and pressure in the reversing layers. .. Saha's theory had dominated all recent progress in the observation and interpretation of stellar spectra.

Curiously enough, the key figures in this development hardly entertained collaboration with Saha, who ever remained an exalted reference in their papers. In contacting Hale, Saha probably had nursed a fond hope of working at the Mt Wilson. But Russell, while communicating to Saha every confirmation of his predictions and begetting him the due recognition, maintained a certain distance from him.

\section{BIBLIOGRAPHY}

Chatterjee, S and Chatterjee, E. Meghnad Saha, National Book Trust, Delhi, 1984.

DeVorkin, D H. Meghnad Saha Birth Centenary Commemoration Volume, ed. S B Kar Mohapatro, SINP, Kolkata, 1993, p. 154.

Eddington, A S. The Internal Constitution of the Stars, Dover, NY, 1926, pp 345-347.

Eggert, J. Phys Z, 20 (1919):570.

Milne, EA, to Saha, 1 June 1921; 24 July 1935, Meghnad Saha Archives (MSA), Saha Institute of Nuclear Physics (SINP).

Mukhopadhyay, A. Abinash Meghnad Saha : Bigyan, Samaj, Rashtra, Anushtup, Kolkata, 2012.

Payne, C. Stellar Atmosphere, Harvard Observatory Monographs, No 1, ed. H Shapley, TheObservatory, Camb, Mass., 1925.

Plaskett, HH. to Saha, 7 January, 1947, MSA.

Russell, H N. PASP 33 (1921) No 194, p 202.

Russell, H N. Astrophys J, 61(1925):38.

Russell Papers, MSA, SINP.

Saha, M N. Phil Mag 40 (1920):472; 809; (1921):267

Saha, M N. Proc Roy Soc (Lond), A99 (1921):135.

Saha, M N. to Hale, 9 July, 1921, MSA.

Saha, M N. to Minnaert, 19 October, 1955, MSA.

Saha, M N. to Plaskett, 21 December, 1946, MSA.

Sen, S N. Professor Meghnad Saha: His Life work and Philosophy, Calcutta, 1954.

Venkataraman, G. Saha and His Formula, Universities Press, 1995. 